\title{
Design and Psychometric Properties of Clinical Nurses Time Management Competency Questionnaire
}

\author{
Mehdi Talebi ${ }^{1}$, Fazlollah Ahmadi*2, Anoshirvan Kazemnejad ${ }^{3}$ \\ 1. PhD Student, Department of Nursing, Faculty of Medical Sciences, Tarbiat Modares University, Tehran, Iran \\ 2. Professor, Department of Nursing, Faculty of Medical Sciences, Tarbiat Modares University, Tehran, Iran \\ 3. Professors, Department of Biostatistics, Faculty of Medical Sciences, Tarbiat Modares University, Tehran, Iran
}

\begin{tabular}{|c|c|}
\hline Article Info & ABSTRACT \\
\hline $\begin{array}{l}\text { Received: 2018/11/05; } \\
\text { Accepted: 2018/12/11; } \\
\text { Published Online: 2019/03/27 } \\
\text { dof }\end{array}$ & $\begin{array}{l}\text { Introduction: Due to the time constraints in the nursing system, it seems } \\
\text { necessary to assess the time management competency of clinical nurses. Time } \\
\text { management has sociocultural nature. Existing time management tools have not } \\
\text { considered social aspects of time management. The purpose of this study was to } \\
\text { design a questionnaire for assessing the social component of time management } \\
\text { competency in clinical nurses population. }\end{array}$ \\
\hline
\end{tabular}

$\underline{10.30699 / \mathrm{sjhnmf} .27 .4 .231}$

Methods: This research was carried out with a explanatory sequential mixed methods design. First, qualitative study and using the grounded theory method, the

Original Article

Use your device to scan and read the article online

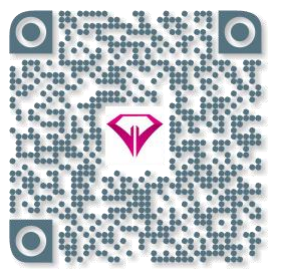
concept of social components of time management competency of clinical nurses was explained. Based on quotations, the items of the initial questionnaire was generated and then the face and content validity was determined by using the quantitative and qualitative methods. The construct validity was determined with the exploratory factor analysis. The reliability was approved with the measurement of internal consistency using Cronbach's alpha coefficient and the stability assessed using a testretest (Interclass correlation coefficient) method..

Results: Of the first 41 items, 36 items entered into the exploratory factor analysis after calculating the impact score of items with values higher than 1.5, content validity ratio higher than 0.53 , content validity index higher than 0.79 , and item analysis. In construct validity step, 29 items was grouped into 6 factors. The internal consistency of the questionnaire was 0.858 and the stability (ICC) of the questionnaire was 0.906 . These 6 factors explained $46.714 \%$ of the variance of the Questionnaire

Conclusion: The questionnaire, according to its designation, can be used to assess the social components of time management competency of clinical nurses.

Keywords: Questionnaire design, Time management, Clinical nurse

Corresponding Information:

Fazlollah Ahmadi, Professor, Department of Nursing, Faculty of Medical Sciences, Tarbiat Modares University, Tehran, Iran. Email: ahmadif@modares.ac.ir

Copyright $\odot$ 2019, This is an original open-access article distributed under the terms of the Creative Commons Attribution-noncommercial 4.0 International License which permits copy and redistribution of the material just in noncommercial usages with proper citation.

\section{How to Cite This Article:}

Talebi M, Ahmadi F, Kazemnejad A. Design and Psychometric Properties of a Tool for Assessing the Clinical Nurses' Time Management Competency. Avicenna J Nurs Midwifery care. 2019; 27 (4):231-241 


\section{طراحى و روانسنجى يرسشنامه ارزيابى شايستگى مديريت زمان يرستاران بالينى}

\section{مهدى طالبى'، فضلالله احمدى'، انوشيروان كاظمنزادّ}

$$
\begin{aligned}
& \text { ا. دانشجوى دكترى برستارى، كروه برستارى، دانشكدة علومبيزشكى، دانشكاه تربيتمدرس، تهران، /يران }
\end{aligned}
$$

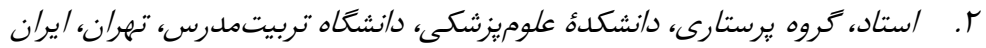

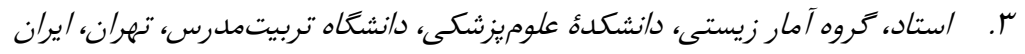

\begin{tabular}{|c|c|}
\hline جكيده & 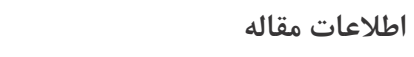 \\
\hline 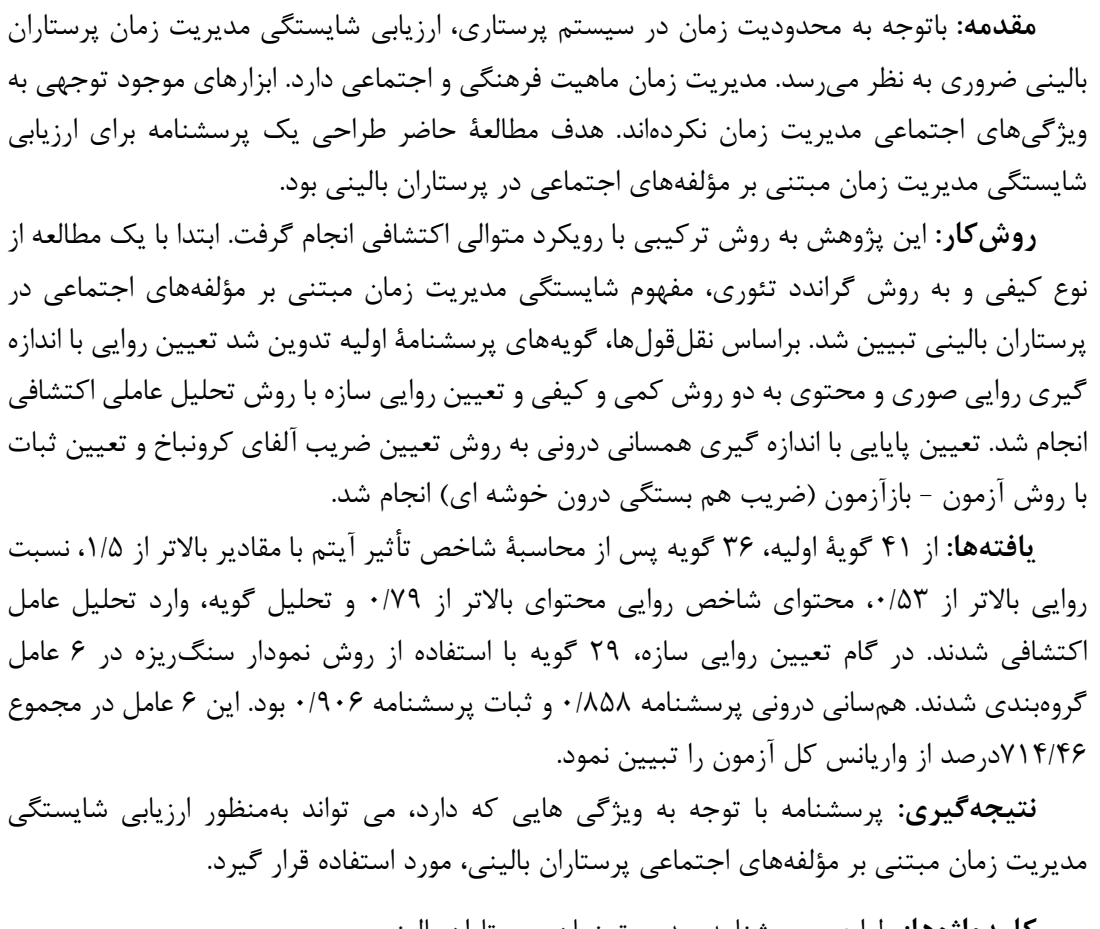 & 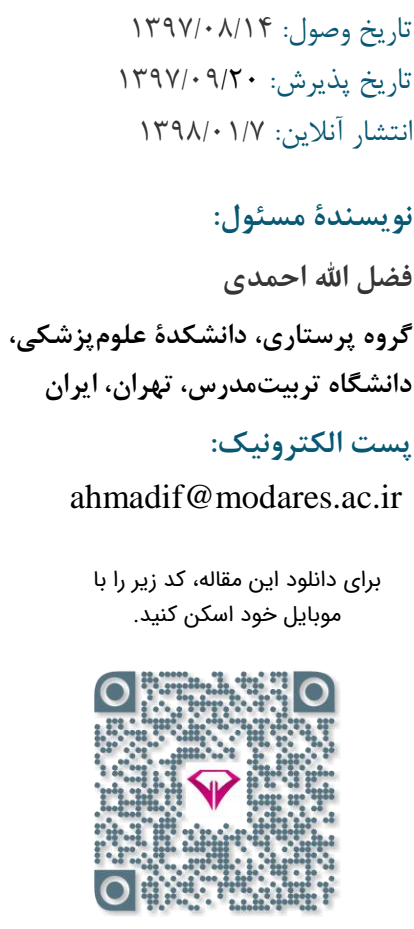 \\
\hline كليدوازهها: طراحى يرسشنامه، مديريت زمان، يرستاران بالينى & \\
\hline
\end{tabular}

بيمار است؛ بنابراين زمان نيز ضرورىترين فاكتور در مديريت

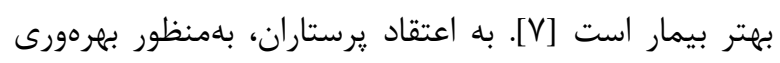

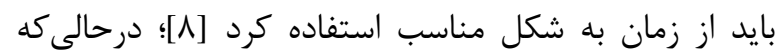

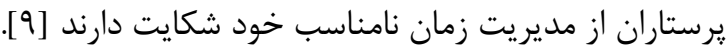

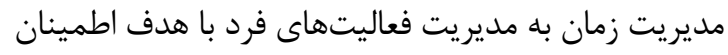
از اينكه فعاليت مدنظر در بازٔ زمانى دردسترس، يا اختصاص

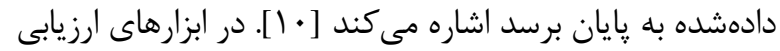

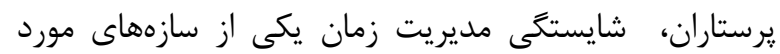

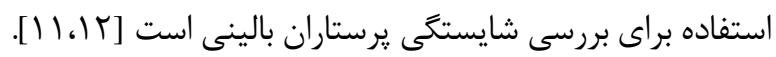

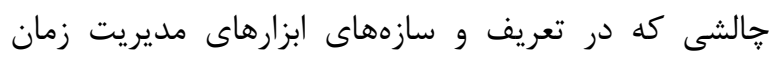

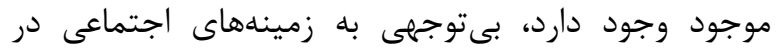
سازمانهاست. در اين ابزارها زمينههاى اجتماعى ماند زماند
در مقولة يرستارى، افزون بر متايار ادايمهاى شخص، سلامت،

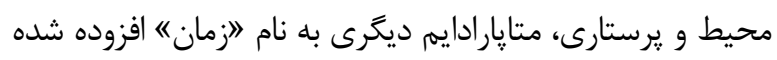

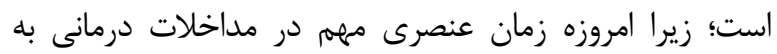

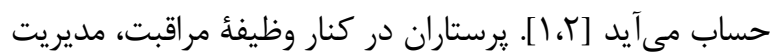

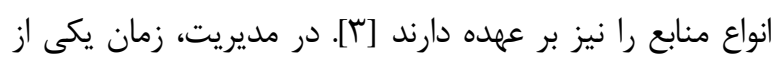
منابع ناملموس است كه نقشى مهم در بهكار كاريرى ساير منابع سازمان دارد [^]]. امروزه سيستمهاى مراقبت از سلامت بدواسطة مدرنشدن و تغييرات نقش يرستاران متعاقب آن، متهمه به

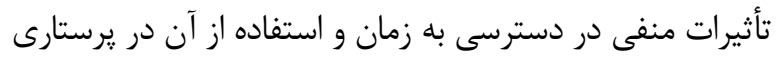

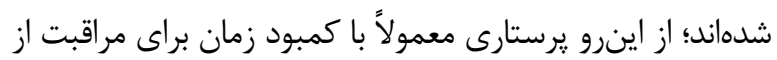
بيمارى توصيف مىشود [ه]. در سيستم يرستارى، زمان همان

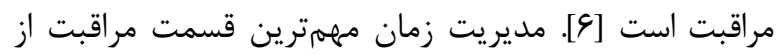


بر اساس اين الكَ، جهار كام اساسى طراحى ابزار بلدرتيب ذيل

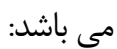
1. انتخاب مدلى مفهومى بلمنظور تعيين ابعاد موضوع مورد

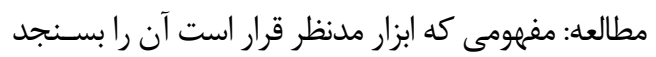
بايـد باروشنى تعريف شود.

r. تعيين اهداف سنجش: واضحسازى اهداف يا همان مشخص كردن حيطههاى مفهـوم. r. تدوين طرح اوليه:تعيين حيطههاى اختصاصىتر قابلاندازمخيرى مفهـوم و تعيين تعداد مناسب آنها. f

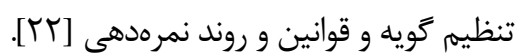

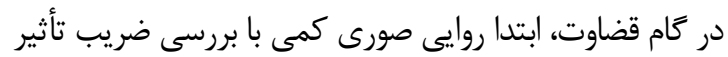

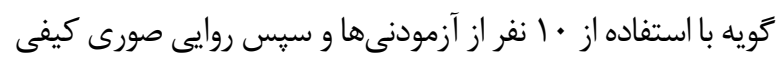

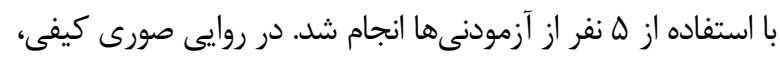
ابهامها و اشكال در درك كلمات، سوءتعبيرها، دشوارى، تناسب آيتم

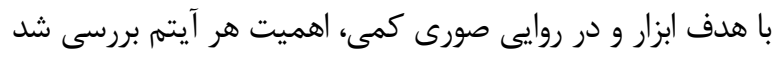

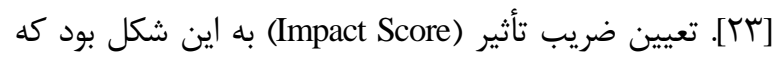
كروه هدف اهميت هر عبارت را در طيف ليكرت له قسمتى شامل

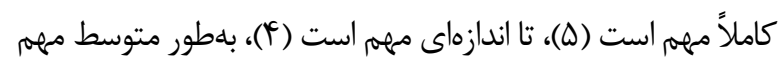

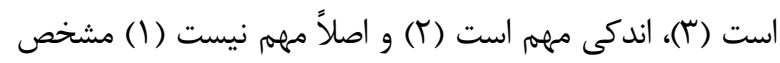

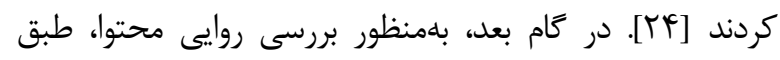

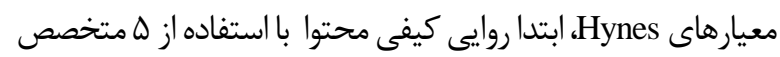

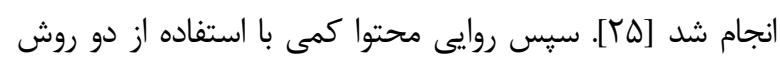

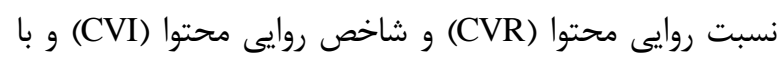
استفاده از نظرات با متخصص ابزارسازى و مديريت يرستارى

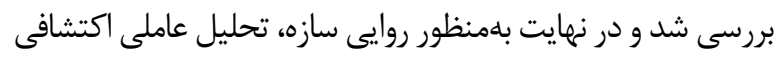

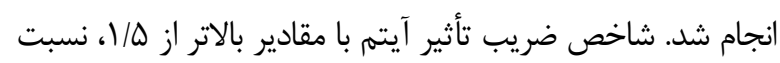

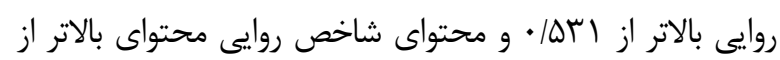

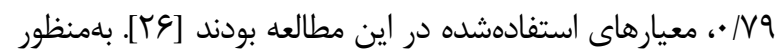

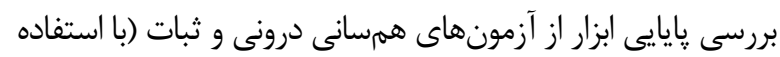

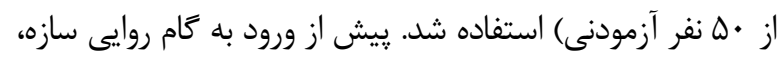

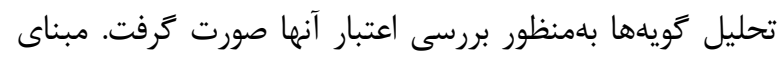

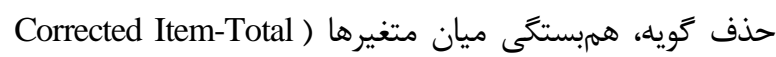
Correlation

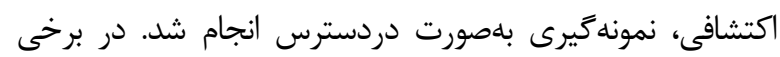

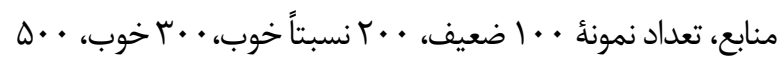

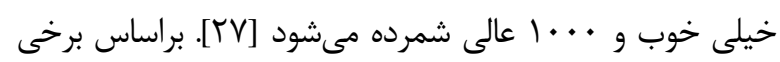

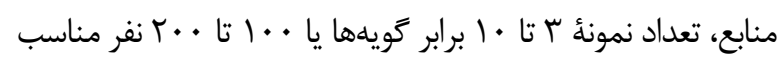

ارتباطات كارى بين همكاران، مديران و مشتريان مدنظر قرار

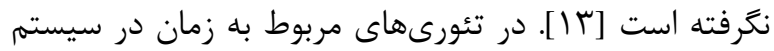
يرستارى به زمينههاى اجتماعى اشاره شده است. يرستاران

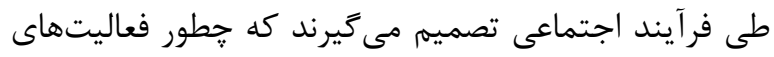
خود را سازماندهى كنند [4 [1]. در سيستم يرستارى، مديريت

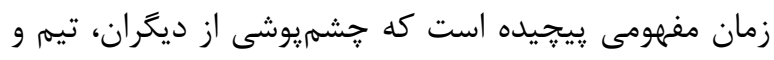

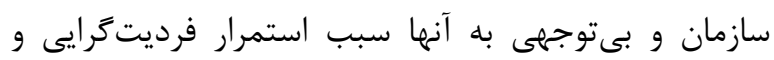

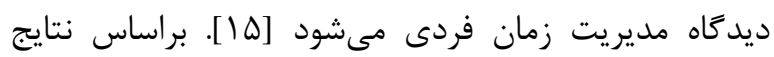
يزوهشها رفتارهاى مديريت زمان به متغيرهاى فردى و ودئ

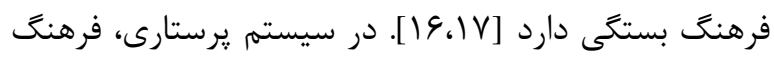

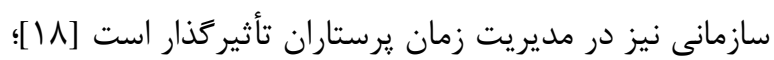

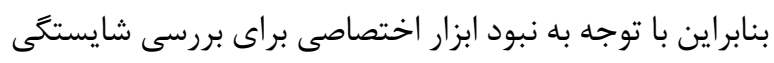

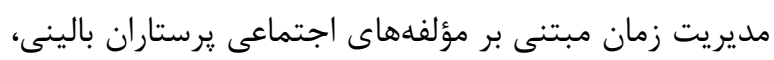

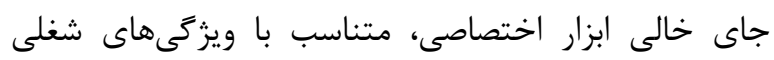

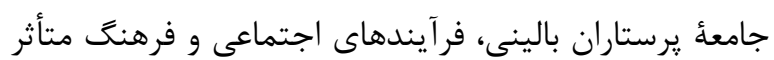

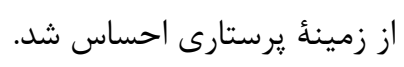

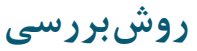

نظر به بى توجهى به فرآيندهاى اجتماعى در ابزارهاى مديريت

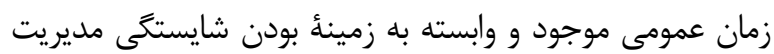

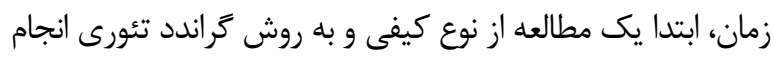

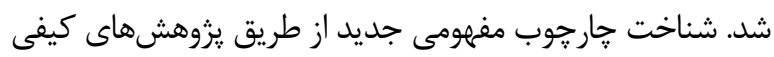

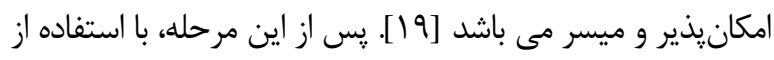

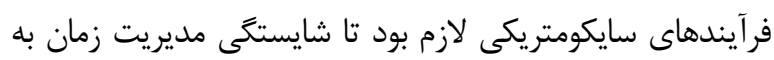
شكل كمى و صحيح اندازهكيرى شود. با توجه به مطالب بيشكَّفت،

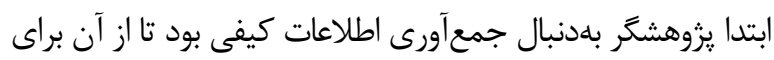

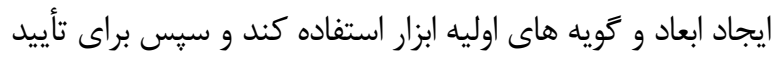
آنها روشهاى كمى بلمنظور تبيين روابط بلدست آمده از يافتهاد إنهاى

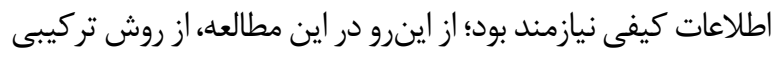

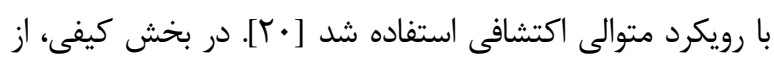

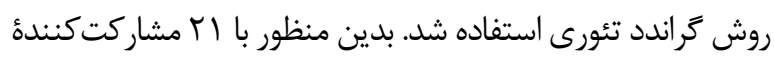

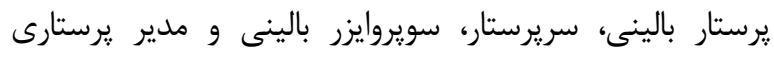

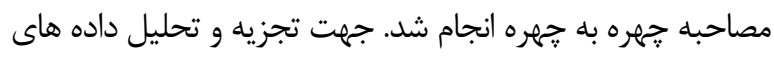

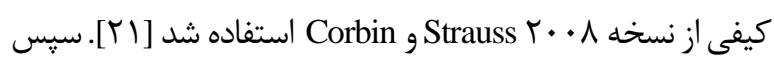
بلمنظور انجامدادن كام دوم مطالعه (طراحى ابزار و روانسنجى آنان)،

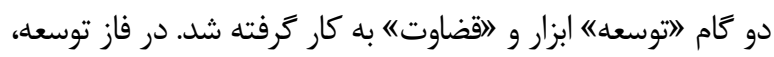

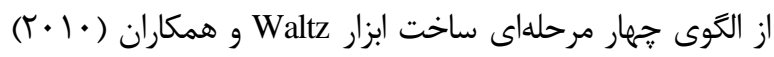

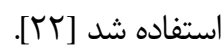


F تأثير برنامة مراقبتى مبتنى بر حضور التيامبخش بر كيفيت زندكى

بافته ها

در بخش روانسنجى مطالعه، 9 9/V درصد مشاركت كنند

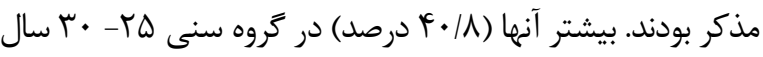
و ه/ إدصد در گروه بالاى • ه سال بودند و به عبارت ديگر كمترين مشاركت را در مطالعه داشتند. همجنين تحصيلات بيشتر مشاركت كنندگان (VA درصد) در سطح كارشناسى بود. افزون بر

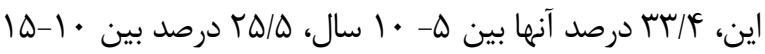

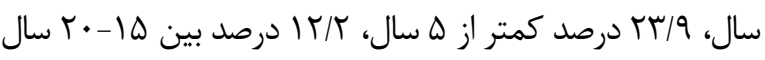

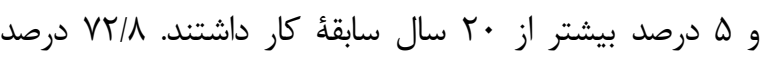
مشاركت كنندگان در بيمارستانهاى دانشگاهى آموزشى، س/ درصد در بيمارستانهاى متعلق به سارمان تأمين اجتماعى، N/9

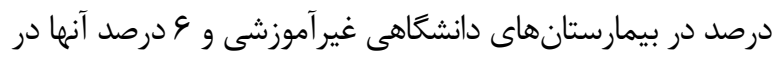
ديخر بيمارستانها (خصوصى، خيريه و...) مشغول به كار بودند. همجنين س/ •r درصد مشاركت كنند

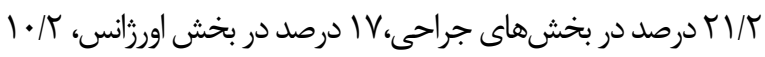

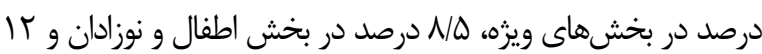
Nرصد بقيه مشاركت كنندكان در ساير بخشها فعاليت داشتند. NoV درصد مشاركت كنند آنها به صورت موردى، آكردصد به صورت وظيفهاى و در بقيه موارد بر

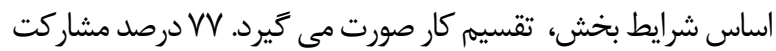
كنندكان يه صورت شيفت در زردش فعاليت ميكردند.

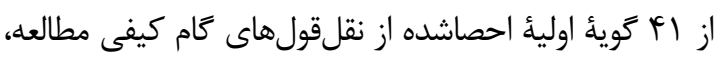

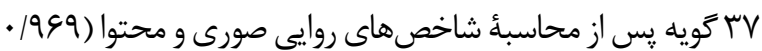
(S-CVI = تحليل عامل اكتشافى شدند. شاخص نمونهگيرى كيسر- ماير-

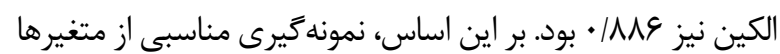

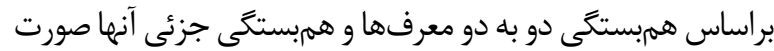

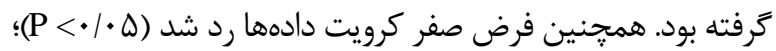
بنابراين نتيجه كرفته شد كه در تحليل عاملى اكتشافى براى دادهها

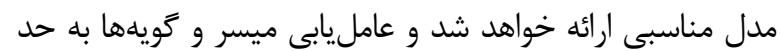
كافى براى بيشخويى عامل ها مناسب مى باشند. در اين مرحله با

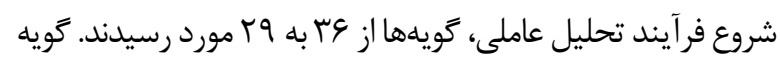
هاى مذكور با استفاده از نمودار سنگريزه (تصوير ()) و معيار واريانس حداقل ه درصد، در \& عامل زروهبندى شدند. به كمك

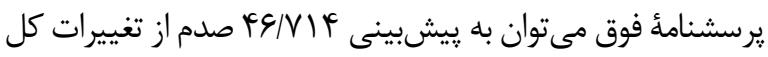
شايستخى مديريت زمان مبتنى بر مؤلفههاى اجتماعى : يرستاران بالينى يرداخت. ضريب آلفاى كرونباخ و ضريب همبستخى درون مرنى

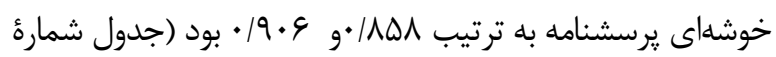

است [YN]]. در يزوهش حاضر، FVA يرسشنامه براى بررسى روايى تكميل شد. بلمنظور تحليل دادهها در ابتداى تحليل عاملى، آزمون شاخص كفايت مناسب اندازهيرى در نمونهها كيسر، ماير و الكين صورت گرفت كه ميزان آن بين صفر و يك متغير است. هر جه ميزان آن بيشتر باشد، تحليل عاملى بهتر خواهد بود. مقادير

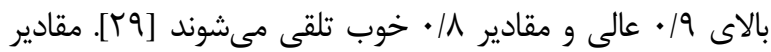

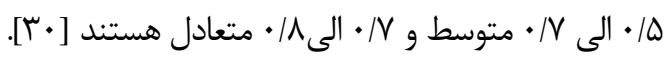
بdمنظور تشخيص اينكه آيا ماتريس همبستگى بلدستآمده تفاوت معنادارى باصفر دارد و بر يايئ آن تحليل عاملى توجيهشدنى

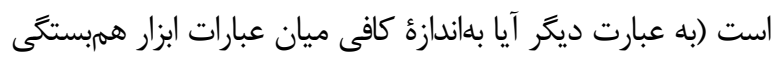

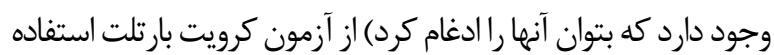
شد. اتر در اين آزمون، فرضئُ صفر رد شود، عامليابى توجيهشدنى

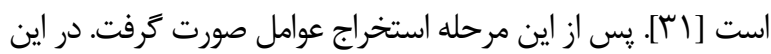

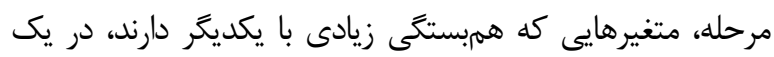

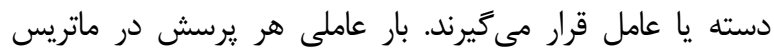

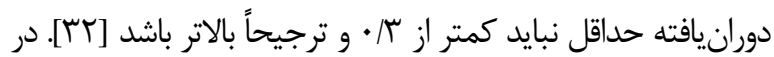
اين مطالعه، شاخص س/• در نظر گرفته شد. بلمنظور تعيين تعداد عوامل قوانين متفاوتى وجود دارد. روش بررسى نمودار سنگريزه براساس نظرئُ كتل يكى از اين روشهاست. در اين روش مىتوان با

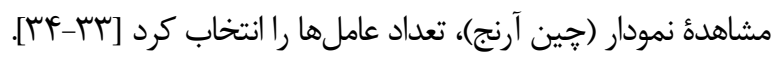

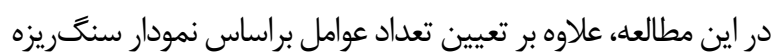
(Scree test)، واريانس بيشتر از ه درصد يكى از معيارهاى ديگر براى تعيين تعداد عوامل ابزار مدنظر قرار داده شد [Wه]. يس از استخراج

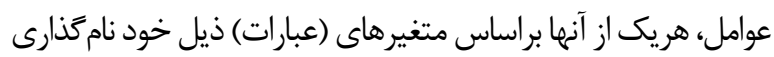
شدند. براساس قانون نشانكر سهتايى (Three indicatorrule) حداقل س گويه به ازاى هر متغير ينهان تعيين شد [צץ]. از سوى ديگر، در

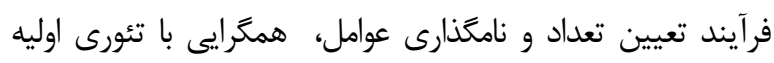

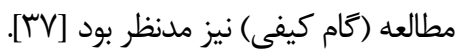
با توجه به اينكه فرض نرمالبودن در دادههاى يرسشنامئ اوليه

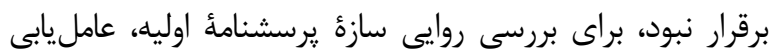

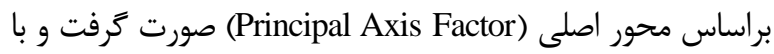
فرض همبستتى عوامل از جرخش يروماكس (Promax) استفاده

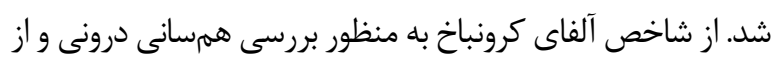

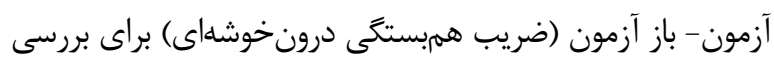

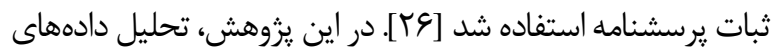
كمى بخش روانسنجى يرسشنامه با استفاده از نرمافزار كPS

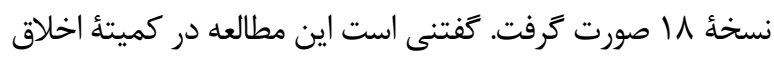
دانشگاه (IR.TMU.REC.1394.152) تأييد شده بود. 
كار اقتضايى و مديريت درخواستهاى ديخران، در كوتاهدت يا بلندمدت به مديريت زمان/ وظايف خود و برحسب مورد و شرايط به مديريت زمان/ وظايف همكاران خود بلمنظور انجام وظايف محولشده به تيم يرستارى اقدام مى كردند.
(1). در اين :زوهش، مديريت زمان ماهيت يويا و اقتضايى داشت. يرستاران بالينى بهمنظور ذخيره زمان، بيشخيرى از اتلاف وقت،

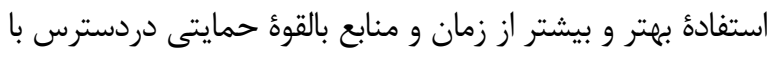
مديريت كنش و واكنشهاى اجتماعى از جمله تعديل مسئوليت و هنجارها، انضباط حرفهاى، مديريت هيجانات، انتقال تجارب، تقسيم

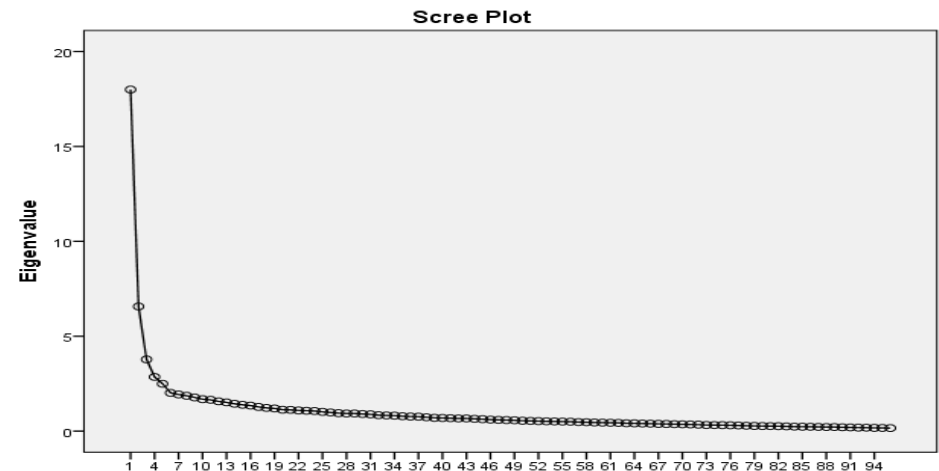

Component Number

تصوير شمارهُ ا. نماى سنََريزه براى استخراج عوامل شايستكى مديريت زمان مبتنى بر مؤلفههاى اجتماعى در يرستاران بالينى

جدول ا. عوامل احصاشده و مقادير مربوط به بار عاملى، درصد واريانس، مقدار ويزه، آلفاى كرونباخ و ضريب درون خوشهاى يرسشنامه

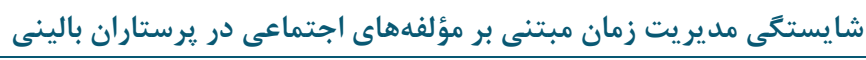

\begin{tabular}{|c|c|c|c|c|c|c|c|}
\hline خريب درون & كرونباخ & وقدار & تراريانس & عاملى & كويهها & & 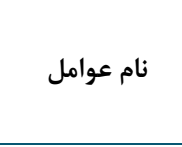 \\
\hline \multirow{6}{*}{. 1191} & \multirow{6}{*}{$\cdot|\lambda| \Lambda$} & \multirow{6}{*}{ GINIT } & \multirow{6}{*}{ rI/GV9 } & - IATF & 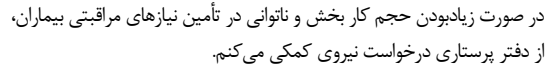 & .1 & \multirow{6}{*}{ هنديل مسئوليت و } \\
\hline & & & & . INIT & دانها، اعلام وضعيت بحرت افزايش غيرمنظرئ تعداد بيماران بدحال و ناتوانى در تأمين نيازهاى & r & \\
\hline & & & & ./VTS & 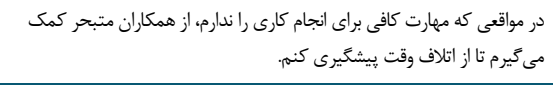 & $r$ & \\
\hline & & & & $\cdot$ - DPFS & برخواست بيماران سالخورده يا ناتوان كه توانايى انجامدادن امور فردى خود را ندارد، & f & \\
\hline & & & & $\cdot / \& \Delta \Lambda$ & كمر مواقعى كه حجم كار زياد است، از همكار انم براى انجامدادن بعضى كارها &.$\Delta$ & \\
\hline & & & & $\cdot / r \cdot 9$ & 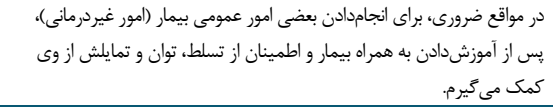 & 9 & \\
\hline \multirow{5}{*}{$.19 \cdot 9$} & \multirow{5}{*}{. /VAr } & \multirow{5}{*}{ F/r人q } & \multirow{5}{*}{$r \Delta / / 91$} & $\cdot \mid 9 \wedge 9$ & 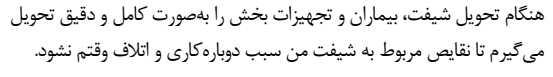 &.$v$ & \multirow{5}{*}{ انضباط حرفهاى } \\
\hline & & & & . ISTV & زودتر ازموعد مقرر محل كارم را ترك نمى كنم. & $\wedge$ & \\
\hline & & & & - I9TA & در اولين فرصت، وظايف خود را آغاز مىكنه. & .9 & \\
\hline & & & & - IGTF & رسانم. ريفت كارى، مراودات اجتماعى غيرضرورى خود را با همكاران به حداقل مى & .1. & \\
\hline & & & & $\cdot / \Delta \cdot r$ & كنم. شيفت كارى، تماسهاى تلفنى شخصى خود را به موارد ضرورى محدود مى & .11 & \\
\hline
\end{tabular}


צr تأثير برنامةٔ مراقبتى مبتنى بر حضور التيامبخش بر كيفيت زندگى

\begin{tabular}{|c|c|c|c|c|c|c|c|}
\hline 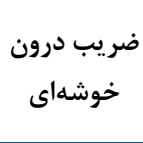 & 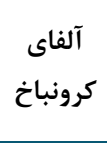 & وقدار & تجمعى درصد & 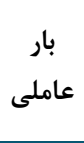 & تويهها & & 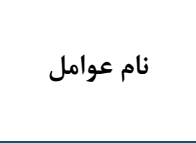 \\
\hline & & & & $\cdot /$ MVT & شوم. ريفت كارى، وارد شبكهاى اجتماعى مجازى (تلكرام، اينستاًرام و...) نمى &.$\pi$ & \\
\hline & & & & $\cdot \pi \Delta v$ & 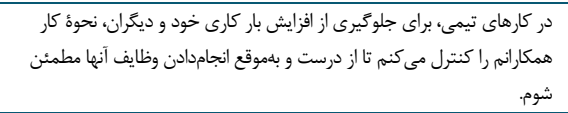 & 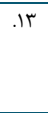 & \\
\hline \multirow{5}{*}{$\cdot / 9 r \Delta$} & \multirow{5}{*}{$\cdot 11 \cdot 9$} & \multirow{5}{*}{ 1/919 } & \multirow{5}{*}{ 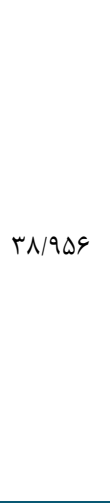 } & ./V१९ & 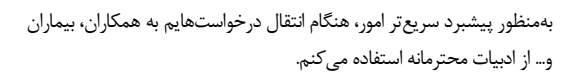 & .14 & \multirow{5}{*}{ مديريت هيجانات } \\
\hline & & & & . NTr & 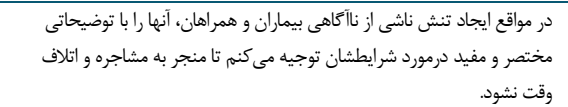 & .10 & \\
\hline & & & & $\cdot / \Delta \wedge \mathrm{r}$ & التاف وقاست منجر رفتار نامناسب بيمار يا همراهان جشميوشى مىكنم تا به مشاجره و & .19 & \\
\hline & & & & $\cdot 10 \cdot 9$ & 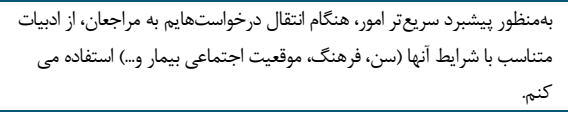 & $.1 \mathrm{~V}$ & \\
\hline & & & & $\cdot / r V A$ & 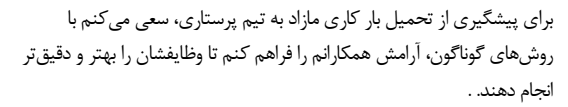 & .11 & \\
\hline \multirow{3}{*}{.$/ 940$} & \multirow{3}{*}{$\cdot / V \vee q$} & \multirow{3}{*}{$1 /$ T4 } & \multirow{3}{*}{$\mid+1 / 49$} & $\cdot / V \notin q$ & 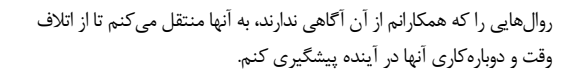 & .19 & \multirow{3}{*}{ 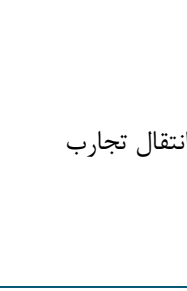 } \\
\hline & & & & - MAT & 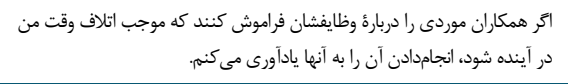 & $r$ & \\
\hline & & & & $\cdot / N T$. & 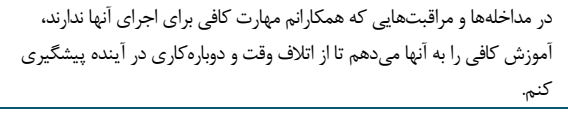 & $r$ & \\
\hline \multirow{4}{*}{.$/ 94 \wedge$} & \multirow{4}{*}{$\cdot \mid \Lambda \cdot 1$} & \multirow{4}{*}{$1 / T \& V$} & \multirow{4}{*}{$F+/ D 11$} & $\cdot / V 99$ & بيش از هر كارى، وظايف را ميان خودم و همكارانم تقسيم مى كنم. & $r$ & \multirow{4}{*}{ تقسيم كار اقتضايى } \\
\hline & & & & $.19 \Delta \Delta$ & 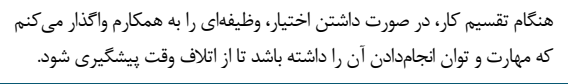 & rr & \\
\hline & & & & .190 & 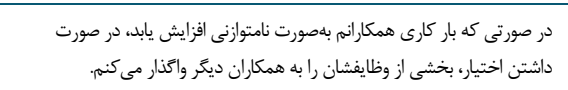 &.$r f$ & \\
\hline & & & & $\cdot \mid \Delta \& F^{C}$ & هر صورتى كه وظايفم را انجام داده باشه، به همكارانى كه از كارهايشان عقب & $r \Delta$ & \\
\hline \multirow{4}{*}{$\cdot / 194$} & \multirow{4}{*}{$\cdot / V V \cdot$} & \multirow{4}{*}{$1 / 19 V$} & \multirow{4}{*}{ fe/VIf } & $\cdot \operatorname{lnta}$ & 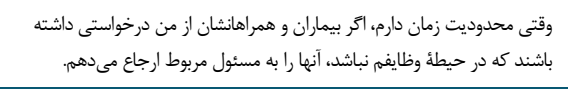 & .49 & \multirow{4}{*}{ درخواست هايتى ديتران } \\
\hline & & & &.$|9|$. & 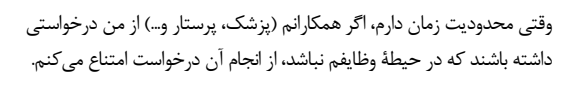 & rV & \\
\hline & & & &.$/ 010$ & انجام مى دهمه. & $r \wedge$ & \\
\hline & & & & $\cdot / 499$ & 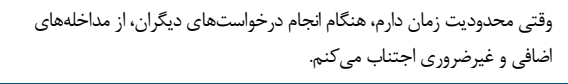 & .99 & \\
\hline
\end{tabular}

درخواستهاى ديخران استخراج شد. شواهد نشان داد يرسشنامه از روايى و يايايى قابل قبولى برخوردار بود.

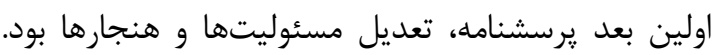

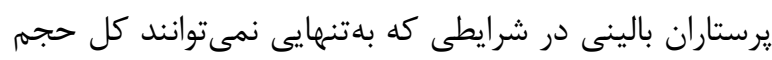

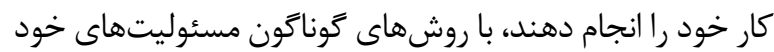

يزوهش حاضر با هدف اطراحى و روانسنجى ابزار ارزيابى شايستخى مديريت زمان مبتنى بر مؤلفههاى اجتماعى در يرستاران بالينى" انجام شد. يرسشنامة نهايى در قالب وج گويه

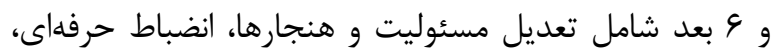
مديريت هيجانات، انتقال تجارب، تقسيم كار اقتضايى و مديريت 
مديريت زمان، همان مديريتكردن خود است و مديريت خود

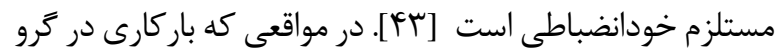

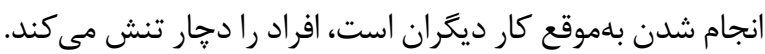

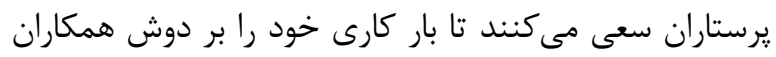
خود نيندازند [ه]. انضباط شخصى يكى از وازمهاى مهمه مديريت

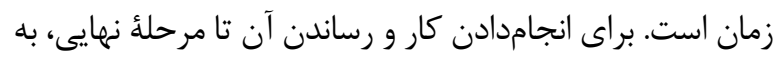

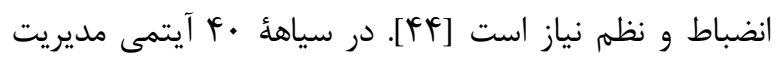

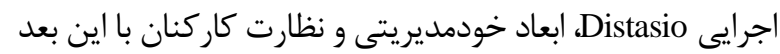

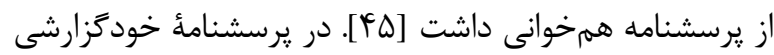

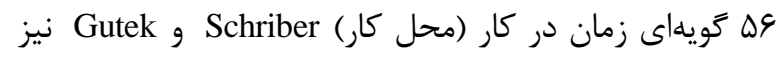

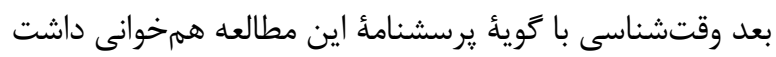

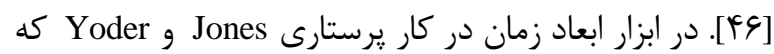

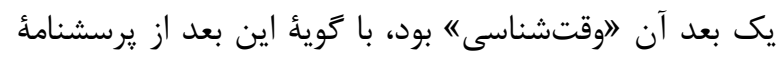

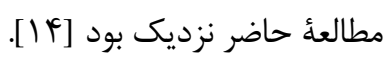

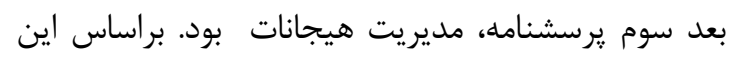

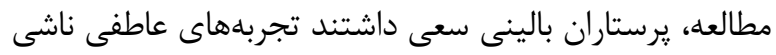

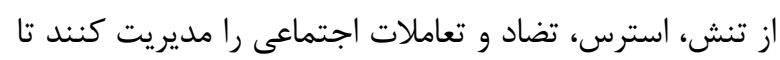

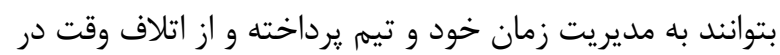
كوتاهمدت و بلندمدت ييشخَيرى كنند. اين راهبرد بيانكر توجه

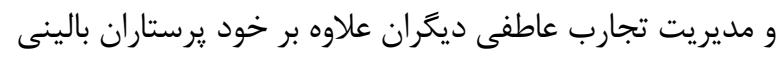

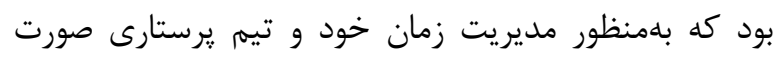
مى گرفت. يكى از مفاهيمى كه بهمنظور مديريت استرس و تننش

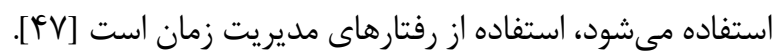

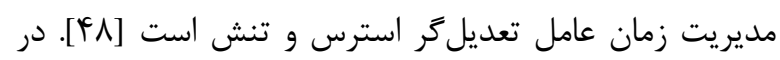

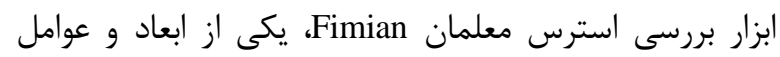

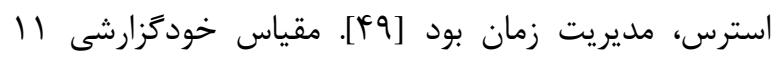
كويهاى مقابله از طريق مديريت زمان ( Time-management Long I, (coping scale

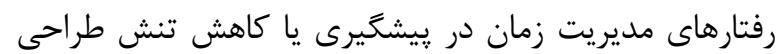

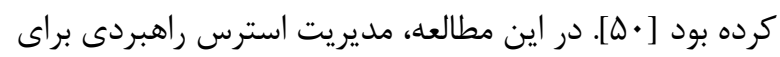

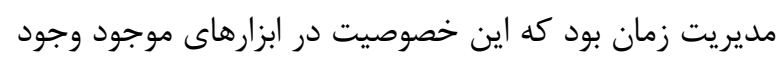
نداشت. بعد جهارم به انتقال تجربهها اشاره داشت. يرستاران بالينى

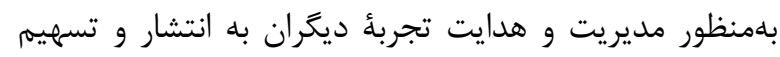

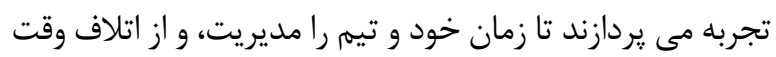
در كوتامدت و بلندمدت وييشگيرى كنند. اين راهبرد مبين

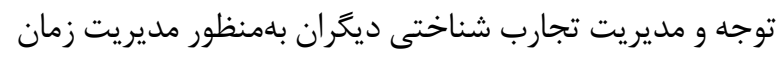

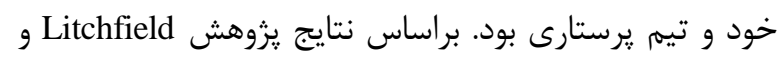

را بازنخرى كرده و كاهش مىدهند. در اين رويكرد، زمينههاى تعديل هنجارهاى رايج در سيستم اجتماعى سيستم درمانى مانند

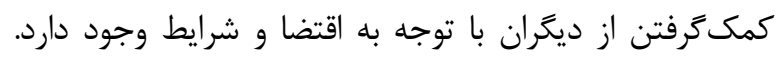

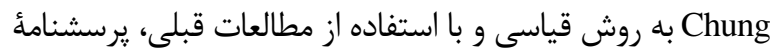
مديريت زمان را طراحى كرده بود كه ابعادى مانند اولويتبندى لئل برنامهريزى، اجرا، كاهش مسئوليت، مصالحه، تنظيم هدف، سر درد

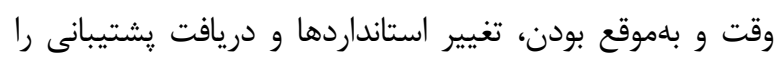

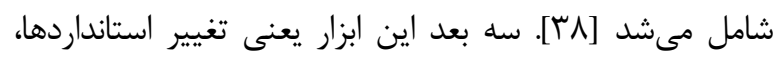

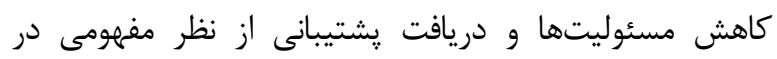

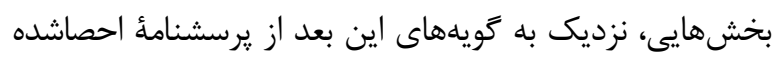

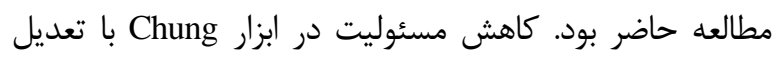
مسئوليت در يرسشنامئ حاضر تفاوت داشت. در ابزار مورد اشاره،

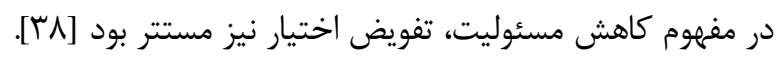

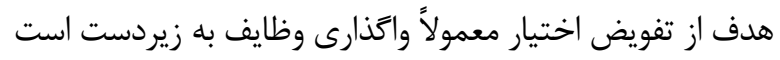

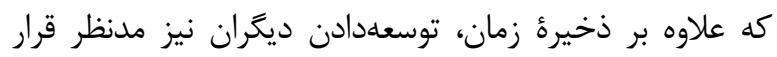

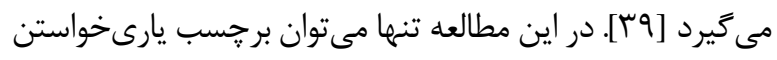

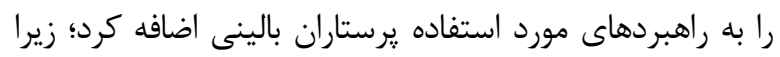

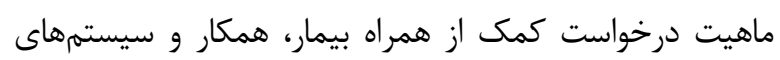

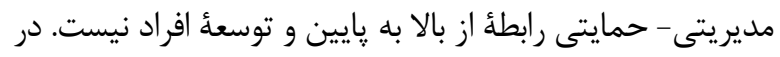

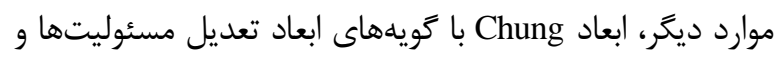

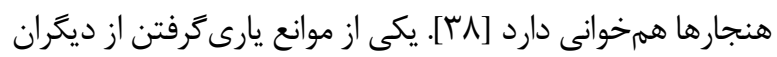

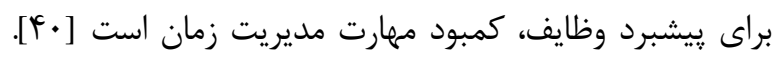

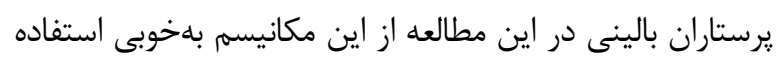

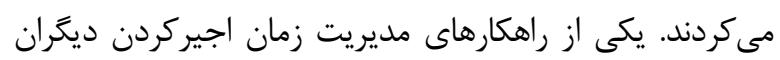

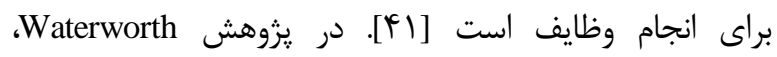

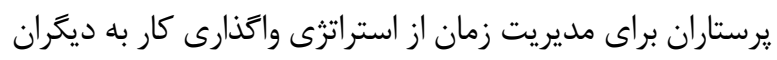

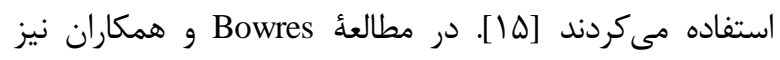

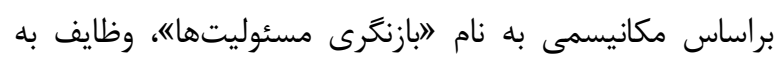

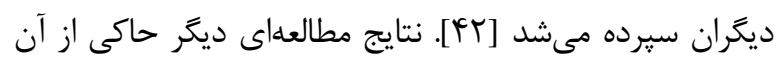

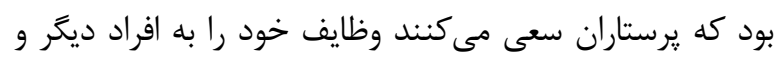
شيفتهاى بعدى منتقل نكنند [ه].

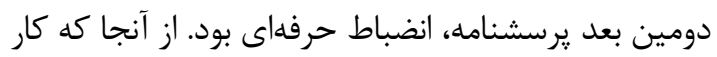

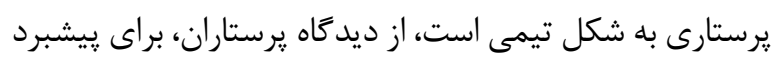

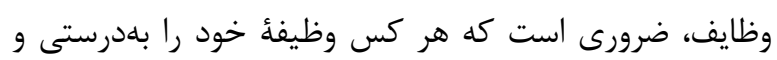

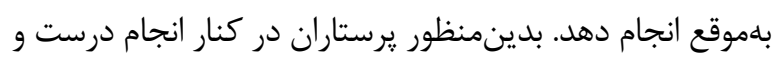

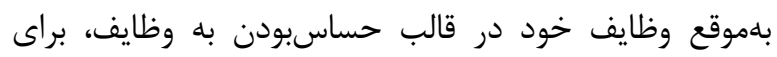

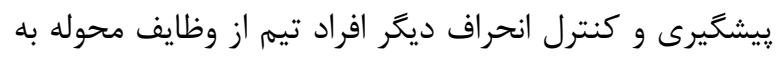
آنها، تلاش مى كنند تا سكتهاى در كار تيمى صورت نتخيرد؛ زيرا 
خواستههاى نامعقول مقاومت مى كردند يا به عبارتى لانه، يا فعلاً نه《 مى كويند كه با ابزار Chung هم خوانى داشت. در ابزار فوق، منظور از كاهش مسئوليت نه كَفتن به ديكران بود [1/ب]. انجام

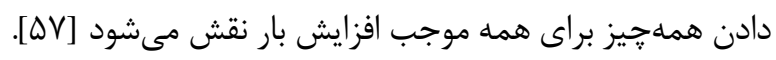

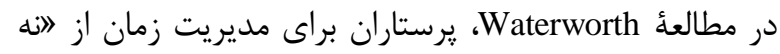
كَفتن و طفرهرفتنه استفاده مى كردند.

\section{نتيجه تيرى}

مديريت زمان ماهيت يويا و اقتضايى دارد. يرستاران بالينى ديرى بلمنظور ذخيرؤ زمان، ييشخيرى از اتلاف وقت، استفادهٔ بهتر و

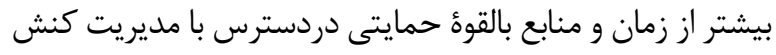

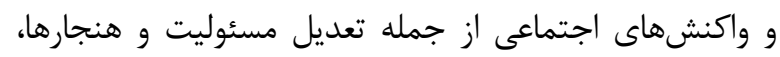

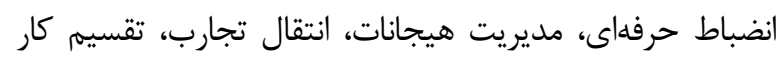
اقتضايى و مديريت درخواستهاى ديكران، در كوتامدت يان

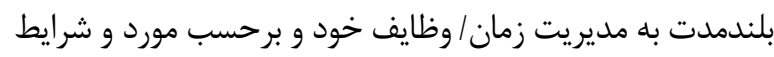

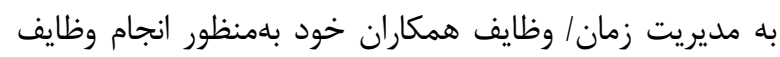
محولشده به تيم يرستارى اقدام مى كنند. با توجه به اينكه نتايج اين مطالعه، حاصل تجربيات يرستاران بالينى مىباشد، مديران

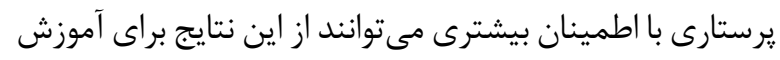

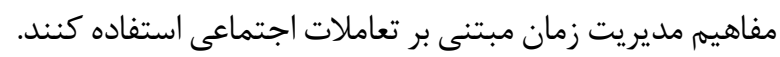
از اين يرسشنامه مىتوان در ارزيابى شايستكى مديريت زمان

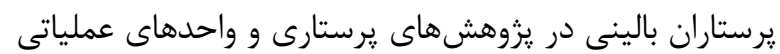

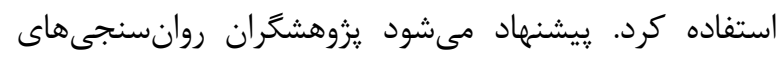
بيشترى درمورد يرسشنامة احصاشده از اين مطالعه، بهمنظور جمع آورى شواهد بيشتر انجام دهند.

\section{سياسگزارى}

از همهٔ مشاركتكنندًان در بخش كيفى و كمى مطالعه

$$
\text { قدردانى مىشود. }
$$

$$
\text { تعارض در منافع }
$$

بين نويسندًان هيجَّونه تعارضى در منافع وجود ندارد

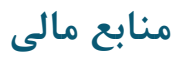

اين مقاله بخشى از رسالهُ دكترى و حامى مالى آن دانشعاه

$$
\text { تربيتمدرس بود. }
$$

Chater افراد وقتى دانش كسب كنند، مىتواند به شكل مؤثر

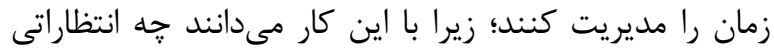

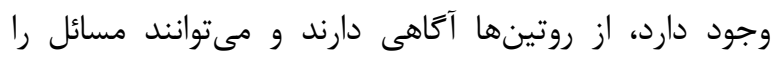

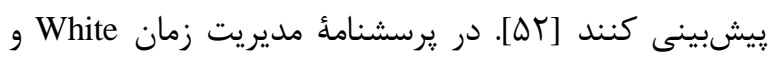

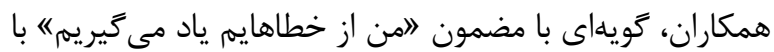

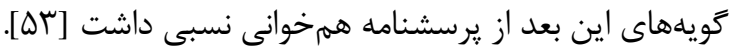

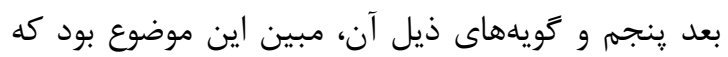
"تقسيم كار اقتضايى" از مهمتر ين شاخص عملكرد يرستاران در زمينهٔ اجتماعى سيستم :رستارى مىباشد. در اين سيستمه،

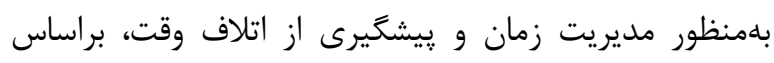

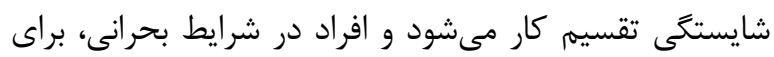
رسيدن به اهداف كل تيم با بر هم زدن معادلات درصدد كمك ترد

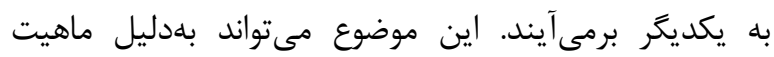

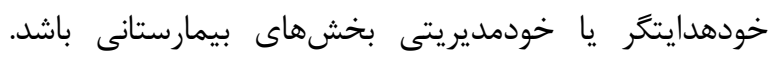
بلهواسطة وظايف كوناكون موجود در تيم، تخصصىسازى در

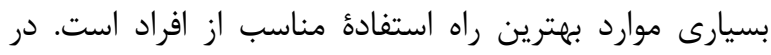

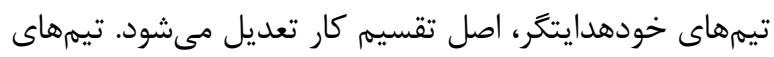

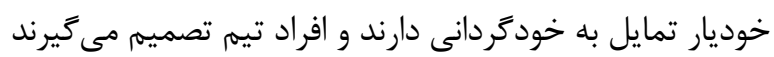

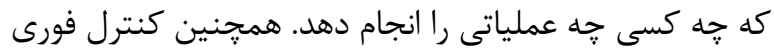

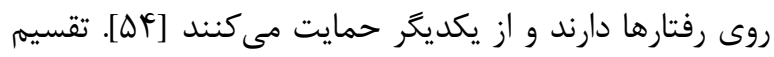

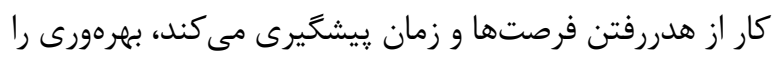
افزايش مىدهد و موجب مىشود هدفها محدودتر شوند؛ درنتيجه فرد با توجه بيشتر به اين هدفهاى محدود،

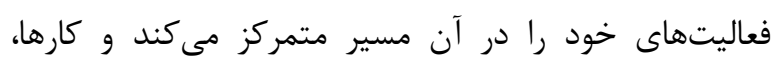
تخصصىتر و با سرعت بيشترى انجام مى شوند [هـ]. همكارى و كار تيمى در مطالعه Chan و همكاران نيز ديده مىشود.

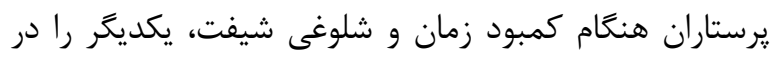
تكميل فعاليتها يارى مى كنند؛ با اين وجود كه تقسيم كار كرده اند [ه]. با توجه به اهميت مديريت زمان تيمى (و نهتنها

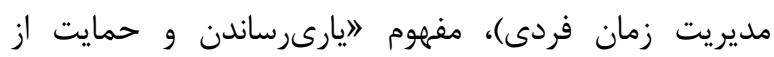

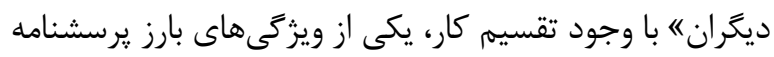

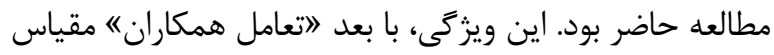

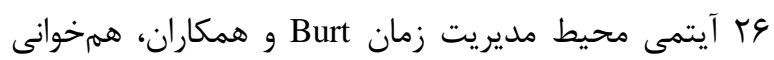

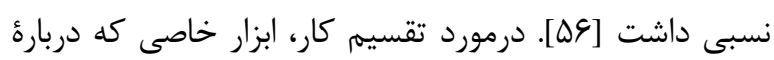

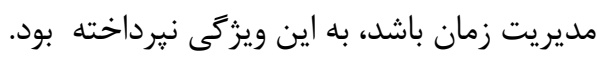

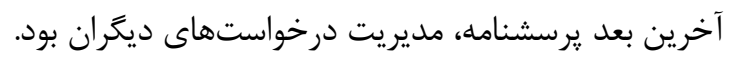
در مطالعه حاضر، يرستاران براى مديريت زمان خود، در برابر 


\section{References}

1. Henly SJ, editor. Routledge international handbook of advanced quantitative methods in nursing research. Routledge; 2015 Jul 24. [DOI: 10.4324/9781315882307]

2. Peterson SJ, Bredow TS, editors. Middle range theories: application to nursing research. Lippincott Williams \& Wilkins; 2009.

3. Garcia SD, Gil RB, Haddad MD, Vannuchi MT, da Costa DB. The role of a nurse in the management of medical-hospital material: an integrative review. Online Brazilian Journal of Nursing. 2013;12(2):41126. [DOI:10.5935/1676-4285.20133791]

4. Elm ZM, SAA, Bagheri H, Marefat D. Relationship individual and organizational skills, time management sport managers in Khuzestan province. Journal of Research in Sport Management and motor behavior. 2013;3(5):73-83.

5. Chan EA, Jones A, Wong K. The relationships between communication, care and time are intertwined: a narrative inquiry exploring the impact of time on registered nurses' work. Journal of Advanced Nursing. $2013 \quad$ Sep;69(9):2020-9. [DOI:10.1111/jan.12064] [PMID]

6. Jones TL. A holistic framework for nursing time: implications for theory, practice, and research. InNursing forum $2010 \mathrm{Jul}$ (Vol. 45, No. 3, pp. 185196). Malden, USA: Blackwell Publishing Inc. [DOI:10.1111/j.1744-6198.2010.00180.x] [PMID] [PMCID]

7. Klemenc-Ketis Z, Kravos A, Poplas-Susič T, Švab I, Kersnik J. New tool for patient evaluation of nurse practitioner in primary care settings. Journal of clinical nursing. $2014 \quad$ May;23(9-10):1323-31. [DOI:10.1111/jocn.12377] [PMID]

8. Dehghan Nayeri N, Nazari AA, Salsali M, Ahmadi F, Adib Hajbaghery M. Iranian staff nurses' views of their productivity and management factors improving and impeding it: a qualitative study. Nursing \& health sciences. 2006;8(1):51-6. [DOI:10.1111/j.14422018.2006.00254.x] [PMID]

9. König CJ, Kleinmann M. Time management problems and discounted utility. The Journal of Psychology. 2007 May 1;141(3):321-34. [DOI:10.3200/JRLP.141.3.321-336] [PMID]

10. Taslimi MS, Sherafat A, Ershadifar A. An evaluation of a managing director's performance in an organization in terms of time. Iranian Journal of Management Studies. 2014 Jul 1;7(2):223-42.

11. Scott K, White K, Johnson C, Roydhouse JK. Knowledge and skills of cancer clinical trials nurses in Australia. Journal of advanced nursing. 2012 May;68(5):1111-21. 2648.2011.05816.x] [PMID]

12. Liou SR, Cheng CY. Developing and validating the Clinical Competence Questionnaire: A selfassessment instrument for upcoming baccalaureate nursing graduates. Journal of Nursing Education and $\begin{array}{lll}\text { Practice. } \quad 2014 & \text { Feb } & \text { 1;4(2):56. } \\ \text { [DOI:10.5430/jnep.v4n2p56] } & & \end{array}$

13. Claessens BJ, Van Eerde W, Rutte CG, Roe RA. A review of the time management literature. Personnel review. $2007 \quad$ Feb 13;36(2):255-76. [DOI: 10.1108/00483480710726136]

14. Jones TL, Yoder LH. Dimensions of nurse work time: Progress in instrumentation. Nursing \& health sciences. 2015;17(3):323-30 [DOI:10.1111/nhs.12191] [PMID]

15. Waterworth $\mathrm{S}$. Time management strategies in nursing practice. Journal of Advanced Nursing. 2003;43(5):432-40. [DOI:10.1046/j.1365. 2648.2003.02740.x] [PMID]

16. Macan T, Gibson JM, Cunningham J. Will you remember to read this article later when you have time? The relationship between prospective memory and time management. Personality and Individual Differences. $2010 \quad$ Apr 1;48(6):725-30. [DOI:10.1016/j.paid.2010.01.015]

17. Mirzaei T, Oskouie F, Rafii F. Nursing students' time management, reducing stress and gaining satisfaction: a grounded theory study. Nursing \& health sciences. 2012 Mar;14(1):46-51. [DOI:10.1111/j.14422018.2011.00661.x] [PMID]

18. Montezeli JH, Peres AM, Bernardino E. Nurse management skills required at an emergency care unit. Revista de Pesquisa: Cuidado é Fundamental Online. 2013;5(3):245-52. [DOI: $10.9789 / 2175$ 5361.2013v5n3p245

19. Oskouie sF, Vehviläinen-Julkunen K, Dabbaghi F, Karimi Moneghi H, Bionghi T. Teaching Styles in Clinical Nursing Education: A Qualitative Approach. Journal of Sabzevar University of Medical Sciences. 2009;15(4):182-91.

20. Creswell JW, Clark VL. Designing and conducting mixed methods research. Sage publications; 2017 Aug 31 .

21. Corbin J, Strauss A. Techniques and procedures for developing grounded theory. Basics of Qualitative Research, 3rd ed.; Sage: Thousand Oaks, CA, USA. 2008.

22. Taghizadeh Z, Ebadi A, Montazeri A, Shahvari Z, al. E. Psychometric properties of health-related measures. part 1: translation, development, and content and face validity. Journal of the Iranian Institute for Health Sciences Research. 2017;16(3):343-57.

23. Zamanzadeh V, Rassouli M, Abbaszadeh A, Majd HA, Nikanfar A, Ghahramanian A. Details of content validity and objectifying it in instrument development. Nursing Practice Today. 2014;1(3):163-71.

24. Bagheri H, Yaghmaei F, Ashtorabi T, Zayeri F. Psychometric properties of Illness Related Worries Questionnaire (IRWQ) in heart failure patients. Iranian Journal of Psychiatric Nursing. 2014;2(1):24-33.

25. Haynes SN, Richard D, Kubany ES. Content validity in psychological assessment: A functional approach to

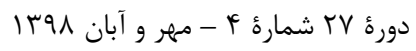


ت تأثير برنامd مراقبتى مبتنى بر حضور التيامبخش بر كيفيت زندگى

concepts and methods. Psychological assessment. 1995 Sep;7(3):238. [DOI:10.1037/1040-3590.7.3.238]

26. Ebadi A, Zarshenas L, Rakhshan M, Zareiyan A, Sharifnia SH, Mojahedi M. Principles of scale development in health science. Tehran: jamee negar. 2017.

27. Mohammadbeigi A, Mohammadsalehi N, Aligol M. Validity and reliability of the instruments and types of measurments in health applied researches. Journal of Rafsanjan University of Medical Sciences. 2015 Mar 15;13(12):1153-70.

28. Waltz CF, Strickland OL, Lenz ER, editors. Measurement in nursing and health research. Springer publishing company; 2010 Apr 17.

29. Munro BH. Statistical methods for health care research. lippincott williams \& wilkins; 2005.

30. Reisy L, Ziaee S, Mohamad E. Designing a questionnaire for diagnosis of vaginismus and determining its validity and reliability. Journal of Mazandaran University of Medical Sciences. 2015 Jun 15;25(125):81-94.

31. Karimi FZ, Zarifnejad G, Abdolahi M, Ali Taghipour A. Surveying the factor structure and reliability of the Persian version of the Jefferson scale of physician empathy-health care provider student version (JSEHPS). Journal of hayat. 2015 Dec 15;21(3):5-14.

32. Ahmad MM, Alasad JA. Predictors of patients' experiences of nursing care in medical-surgical wards. International Journal of Nursing Practice. 2004 Oct;10(5):235-41. [DOI:10.1111/j.1440172X.2004.00484.x] [PMID]

33. Watson R, Thompson DR. Use of factor analysis in Journal of Advanced Nursing: literature review. Journal of advanced nursing. 2006 Aug;55(3):330-41. [DOI:10.1111/j.1365-2648.2006.03915.x] [PMID]

34. Burns N, Grove S. The Practice of Nursing Research Conduct, Critique and Utilization Pennsylvania: Saunders; 2006.

35. Polit DF, Beck CT. Nursing research: Generating and assessing evidence for nursing practice. Lippincott Williams \& Wilkins; 2008.

36. Plichta SB, Kelvin EA, Munro BH. Munro s statistical methods for health care research. Wolters Kluwer Health/Lippincott Williams \& Wilkins, 2013.

37. Carpenter S, Grant AE, Hoag A. Journalism degree motivations: the development of a scale. Journalism \& Mass Communication Educator. 2016 Mar;71(1):5-27. [DOI:10.1177/1077695814551835]

38. Chung YL. Time management strategy, job satisfaction, research productivity, and life satisfaction of university faculty. 1988.

39. Morsy SM. Relationship between time management skills and effective delegation among the head nurses at Assuit university hospitals. AAMJ. 2010 Sep;8(3).
40. Bentil EE, Bentil W. Understanding the help seeking behavior of Accra Polytechnic students: A qualitative approach. Public Health. 2015;5(6):172-85.

41. Kelly P, Tazbir J. Essentials of Nursing Leadership \& Management: Cengage Learning; 2013.

42. Bowers BJ, Lauring C, Jacobson N. How nurses manage time and work in long-term care. Journal of Advanced Nursing. 2001 Feb 18:33(4):484-91. [DOI:10.1046/j.1365-2648.2001.01686.x] [PMID]

43. Black BP. Professional Nursing: Concepts \& Challenges: Elsevier; 2013.

44. hoseini shamloo. Time management. Iran Journal of Nursing. 2000;13(24):49-56.

45. Distasio AW. Time Management, Leadership Styles, and Selected Demographic Factors of Connecticut School Superintendents 1986.

46. Schriber JB, Gutek BA. Some time dimensions of work: Measurement of an underlying aspect of organization culture. Journal of applied psychology. 1987 Nov;72(4):642. [DOI:10.1037/00219010.72.4.642]

47. Pahlevani M, Ebrahimi M, Radmehr S, Amini F, Bahraminasab M, Yazdani M. Effectiveness of stress management training on the psychological well-being of the nurses. Journal of medicine and life. 2015;8(Spec Iss 4):313.

48. Jex SM, Elacqua TC. Time management as a moderator of relations between stressors and employee strain. Work \& Stress. 1999 Apr 1;13(2):182-91. [DOI:10.1080/026783799296138]

49. Kourmousi N, Darviri C, Varvogli L, Alexopoulos EC. Teacher Stress Inventory: validation of the Greek version and perceived stress levels among 3,447 educators. Psychology research and behavior management. 2015;8:81 [DOI:10.2147/PRBM.S74752] [PMID] [PMCID]

50. Lang D. Preventing short-term strain through timemanagement coping. Work \& Stress. 1992 Apr 1;6(2):169-76. [DOI:10.1080/02678379208260351]

51. Schuler RS. Managing stress means managing time. Personnel Journal. 1979 Jan 1;58(12):851-4.

52. Litchfield C, Chater K. Can i do everything? Time management in neonatal unit. Australian Journal of Advanced Nursing, The. 2007 Dec;25(2):36.

53. White SM, Riley A, Flom P. Assessment of Time Management Skills (ATMS): A practice-based outcome questionnaire. Occupational Therapy in Mental Health. 2013 Jul 1;29(3):215-31. [DOI:10.1080/0164212X.2013.819481]

54. Swansburg RC, Swansburg RJ. Introduction to management and leadership for nurse managers. Jones \& Bartlett Learning; 2002.

55. Khadivar H, Lotfian N. The Time Managementin Ferdowsi's Shahname. Journal of Pedagogic and Lyric in Persian Language and Literature Studies Quarterly. 2014;6(19):143-64. 
مهدى طالبى و همكاران TFI

56. Burt CD, Weststrate A, Brown C, Champion F. Development of the time management environment (TiME) scale. Journal of Managerial Psychology. 2010 Aug 17;25(6):649-68. [DOI: 10.1108/02683941011056978]

57. McCallin AM, Frankson $\mathrm{C}$. The role of the charge nurse manager: a descriptive exploratory study. Journal of Nursing Management. 2010 Apr;18(3):31925. [DOI:10.1111/j.1365-2834.2010.01067.x] [PMID] 